\title{
Electrochemical Determination of the Corrosion Resistance of NiCr Dental Casting Alloys
}

\author{
D. Mareci, A. Cailean, G. Ciurescu and D. Sutiman*
}

\author{
Technical University "Gh. Asachi” Iasi, Faculty of Chemical Engineering and Environmental Protection, Bd. D. \\ Mangeron, No. 71, Area Code 700050, Iasi, Romania
}

\begin{abstract}
Based on the polarization curves and electrochemical impedance spectroscopy (EIS) in the case of four commercial dental alloys (Wirolloy, Heraenium, NicromalSoft and VeraSoft) maintained in $0.1 \mathrm{M} \mathrm{NaCl}$ solution, it was established the type and the intensity of the corrosion process by means of the corrosion currents value. The passivation of all the samples occurred spontaneously at the open circuit potential. The corrosion currents value decrease after the alloys maintenance in the corrosive medium due their passivation. The corrosion currents have values of nA order for all the samples and decrease with the increase of the immersion time. The alloys Heraenium and Wirolloy are in the optimum corrosion resistant condition. The VeraSoft and NicromalSoft alloys presented a dangerous breakdown potential (about 200-300 $\mathrm{mV})$. The EIS results show that all NiCr-based alloys exhibits passivity at open circuit potential. The Heraenium and Wirolloy alloys with dendritic microstructure show the best electrochemical behaviour in $0.1 \mathrm{M} \mathrm{NaCl}$ solutions.
\end{abstract}

Keywords: $\mathrm{NiCr}$ dental alloys, open circuit potential, corrosion current, potentiodynamic polarisation curves, EIS.

\section{INTRODUCTION}

Metallic materials play an essential role in repair or replacement of the diseased or damaged bone tissue. The metals are more suitable for load-bearing applications compared with ceramics or polymeric materials because they combine high mechanical strength with fracture toughness [1]. However, the main limitation of these metallic materials is the release of the toxic metallic ions that can lead to various adverse tissue reactions and/or hypersensitivity reactions [2]. The high costs of precious metals and alloys have led to the development of various base-alloy materials, which are more economical. The most important elements of these alloys are: nickel, cobalt, chromium, copper, iron and titanium $[3,4]$. The main difference between the noble and non-noble alloys is that the last are less thermodynamically stable and therefore their corrosion resistance depends on the formation of a thin, protective oxide film (passive film) on the surface of the material. If the oxide film is disrupted, then the metal or alloy must repassivate in order to be protected [3]. NiCr-based and CoCr-based are the most commonly used metal-based alloys in dentistry. These materials are currently used for crowns, bridges casting and denture bases. Ni-based alloys are commonly used as the substructure of metallic-ceramic crown and were introduced into dentistry as possible replacement for precious alloys due to the increasing cost of gold throughout the 1980s [5]. Nibased alloys offer the advantage of an increased modulus of elasticity comparatively with gold that allows thinner sections of alloy to be used and consequently less tooth destruction during the crown preparation.

*Address correspondence to this author at the Technical University "Gh. Asachi" Iasi, Faculty of Chemical Engineering and Environmental Protection, Bd. D. Mangeron, No. 71, Area code 700050, Iasi, Romania; Tel: 0040278683/2107; Fax: 0040232271311;

E-mail: sutiman@tuiasi.ro
Chromium is the main alloying element in Ni-based alloys and is added to promote the formation of a stable passive oxide layer that is highly resistant to corrosion [6]. Molybdenum is also frequently added to promote resistance to pitting and crevice corrosion [6, 7]. In commercial alloys, the composition of $\mathrm{Cr}$ and Mo ranges from 11 to 25 (wt \%). Alloys that contain lower amounts of $\mathrm{Cr}$ and Mo are reported to be more susceptible to corrosion [8].

Surface analysis of the passive oxide film formed on the surface of Ni-based alloys has related higher corrosion rates to lower proportions of $\mathrm{Cr}$ and $\mathrm{Mo}$ in the film $[9,10]$. The presence of crevices combined with an inhomogeneous distribution of $\mathrm{Cr}$ in the microstructure can lead to accelerate corrosion of Ni-based alloys with lower $\mathrm{Cr}$ contents. This effect can be avoided by increasing the $\mathrm{Cr}$ content of the alloy [11].

In terms of biomaterials applications, the most inconvenient aspect is the degradations, which occurs due to the material interaction with body or physiological fluids with concentration of about $1 \mathrm{wt} \% \mathrm{NaCl}$ [12-15]. Corrosion manifestations on dental alloys might exhibit biological, functional and esthetic effects and the biological effects have the greatest significance. The oral environment is particularly favorable for the biodegradation of metals due to its ionic, thermal, microbiological and enzymatic properties and it can be presumed that the patient is always exposed to a certain quantity of products of the corrosion process. If these products are not biocompatible, the organism may be injured due the toxicity and sensitization risk. Therefore, the ultimate goal must be to use only those alloys with minimal metal ion release. The release of ions depends upon the corrosion rate of the alloy and the solubility of the corrosion products $[3,16]$.

When NiCr-based alloys are used in restorative procedures, the crowns are placed in the close proximity of the gingival and often extend sub-gingival and the metal 
release through corrosion processes may cause adverse reactions [17-19]. It has been reported that the corrosion products from NiCr-based alloys do not affect cellular morphology or viability but that they do decrease cellular proliferation [20]. The metal ions released from $\mathrm{NiCr}$-based dental casting alloys interfere with cellular energy metabolism [21].

Nickel is an allergen, but there is no evidence that individual patients are at a significant risk of developing sensitivity solely due the contact with nickel-containing dental appliances and restorations. Hypersensitivity reactions to nickel are only likely to occur with prior sensitization from non-dental contacts and even these are rare [22]. Though the allergic properties of the metal ions of NiCrbased alloys should be considered carefully, these alloys still remain very popular for dental use.

The electrochemical behaviour of some NiCr alloys in artificial saliva was reported [23, 24]. Recently, Martins et al. have reported a high corrosion resistance of titanium alloy with dendritic structures in $0.9 \% \mathrm{NaCl}$ solution [25].

The present paper made a comparative study of four $\mathrm{NiCr}$ dental alloys: Heraenium (Heraeus Kulzer, Germany), Wirolloy (Bego, Germany), VeraSoft (Aalba Dent, USA) and NicromalSoft (IMNR, Romania), regarding the electrochemical behaviour in $0.1 \mathrm{M} \mathrm{NaCl}$ solution.

\section{EXPERIMENTAL}

\subsection{Materials}

Four non-precious cast NiCr-based alloys used in dental prosthetics construction were investigated. Their compositions are shown in Table $\mathbf{1 .}$

Table 1. Chemical Composition of the NiCr-Based Alloys

\begin{tabular}{|c|c|}
\hline Alloy & Main Components (wt \%) \\
\hline \hline Heraenium & $59.3 \mathrm{Ni} 24 \mathrm{Cr} 10 \mathrm{Mo} 2 \mathrm{Fe} 2 \mathrm{Mn} 1 \mathrm{Nb}$ \\
\hline Wirolloy & $63.5 \mathrm{Ni} 23 \mathrm{Cr} 9 \mathrm{Fe} 3 \mathrm{Mo} 1 \mathrm{Si} 0.5 \mathrm{Mn}$ \\
\hline VeraSoft & $53.6 \mathrm{Ni} 19.5 \mathrm{Mn} 14.5 \mathrm{Cr} 9.5 \mathrm{Cu} 1.6 \mathrm{Al} 1.5 \mathrm{Si}$ \\
\hline NicromalSoft & $64.6 \mathrm{Ni} 17.8 \mathrm{Cr} 9.8 \mathrm{Cu} 3.5 \mathrm{Mn} 1.8 \mathrm{Si} 1.5 \mathrm{Al} 0.5 \mathrm{Ti} 0.5 \mathrm{Fe}$ \\
\hline
\end{tabular}

\subsection{Microstructure Characterisation}

To study the microstructure of the alloys their surface was chemically treated in agreement with standard procedures. In this case, the chemical attack was realized with a $\left(10 \mathrm{~mL} \mathrm{HNO}_{3}+20 \mathrm{~mL} \mathrm{HCl}+30 \mathrm{~mL}\right.$ glycerol $)$ solution [26]. The treated surfaces were examined by optical microscopy, with an OLYMPUS PME 3- ADL apparatus.

\subsection{Electrochemical Measurements}

The samples were cut into $1 \mathrm{~cm}^{2}$ size and brass nut attached to each experiments using conductive paint to ensure electrical conductivity. The assembly was then embedded into an epoxy resin disk. Then the samples were ground with $\mathrm{SiC}$ abrasive paper up to 1000 grit, final polishing was done with $1 \mu \mathrm{m}$ alumina suspension. The samples were degreased with ethyl alcohol followed by ultrasonic cleaning with deionised water and dried under a hot air stream.

The tests were carried out with the samples immersed in a solution of $0.1 \mathrm{M} \mathrm{NaCl}$ under a neutral $\mathrm{pH}$ range (of about 6.9), at $25 \pm 1{ }^{\circ} \mathrm{C}$, and under air atmosphere.

The assembled specimen was placed in a glass corrosion cell, which was filled with freshly prepared electrolyte (within 24 hours). A saturated calomel electrode (SCE) was used as the reference electrode and a platinum coil as the counter electrode. All potentials referred to in this article are with respect to SCE.

All the electrochemical measurements were performed with a PAR (Princeton Applied Research, USA) 263 A potentiostate connected with a PAR 5210 lock-in amplifier controlled by a personal computer and specific software (Electrochemistry Power Suite, PAR).

For each specimen, 24 hours open circuit potential, $\mathrm{E}_{\mathrm{OC}}$, measurement was performed initially followed by the linear potentiodynamic polarization measurement. These tests were conducted by stepping the potential using a scanning rate 0.5 $\mathrm{mV} / \mathrm{s}$ from $-600 \mathrm{mV}$ (SCE) to $+1200 \mathrm{mV}$ (SCE). Using an automatic data acquisition system, the potentiodynamic polarization curves were plotted and both corrosion current density $\left(i_{\text {corr }}\right)$ and zero current potential (ZCP) were estimated by Tafel plots by using both anodic and cathodic branches. In addition, for evaluate the stability of passivation, passivation current density $\left(i_{\text {pass }}\right)$ and breakdown potential $\left(\mathrm{E}_{\mathrm{bd}}\right)$ were obtained from the potentiodynamic polarization curves.

Surface morphologies of the NiCr-based alloys after the linear potentiodynamic tests were observed using an optical microscope (OLYMPUS PME 3- ADL).

Electrochemical impedance spectroscopy (EIS) was also used to evaluate the samples. The alternating current (AC) impedance spectra for $\mathrm{NiCr}$-based alloys were obtained at the open circuit potential, with a scan frequency range of 100 $\mathrm{kHz}$ to $10 \mathrm{mHz}$ with amplitude of $10 \mathrm{mV}$. The EIS spectra were obtained at $1 \mathrm{~min}, 1$ hour and 1 day after the electrode was immersed in the aerated solutions. In order to supply quantitative support for discussions of these experimental EIS results, an appropriate model (ZSimpWin-PAR, USA) for equivalent circuit (EC) quantification has also been used.

All experiments were performed three times.

\section{RESULTS AND DISCUSSION}

\subsection{Microstructure Characterisation}

The microstructure of the four NiCr-based alloys after chemical attack is shown in Fig. (1). The surfaces of Heraenium and Wirolloy cast alloys showed dendrite microstructure, a rippled structure between the matrix and particle phases.

The microstructure of NicromalSoft alloy contains equiaxial grains with interdendritics particles. The VeraSoft alloy has a complex two-phase structure.

\subsection{Electrochemical Measurements}

When an alloy is placed in the oral environment, an electrochemical interaction (corrosion) between alloy and 

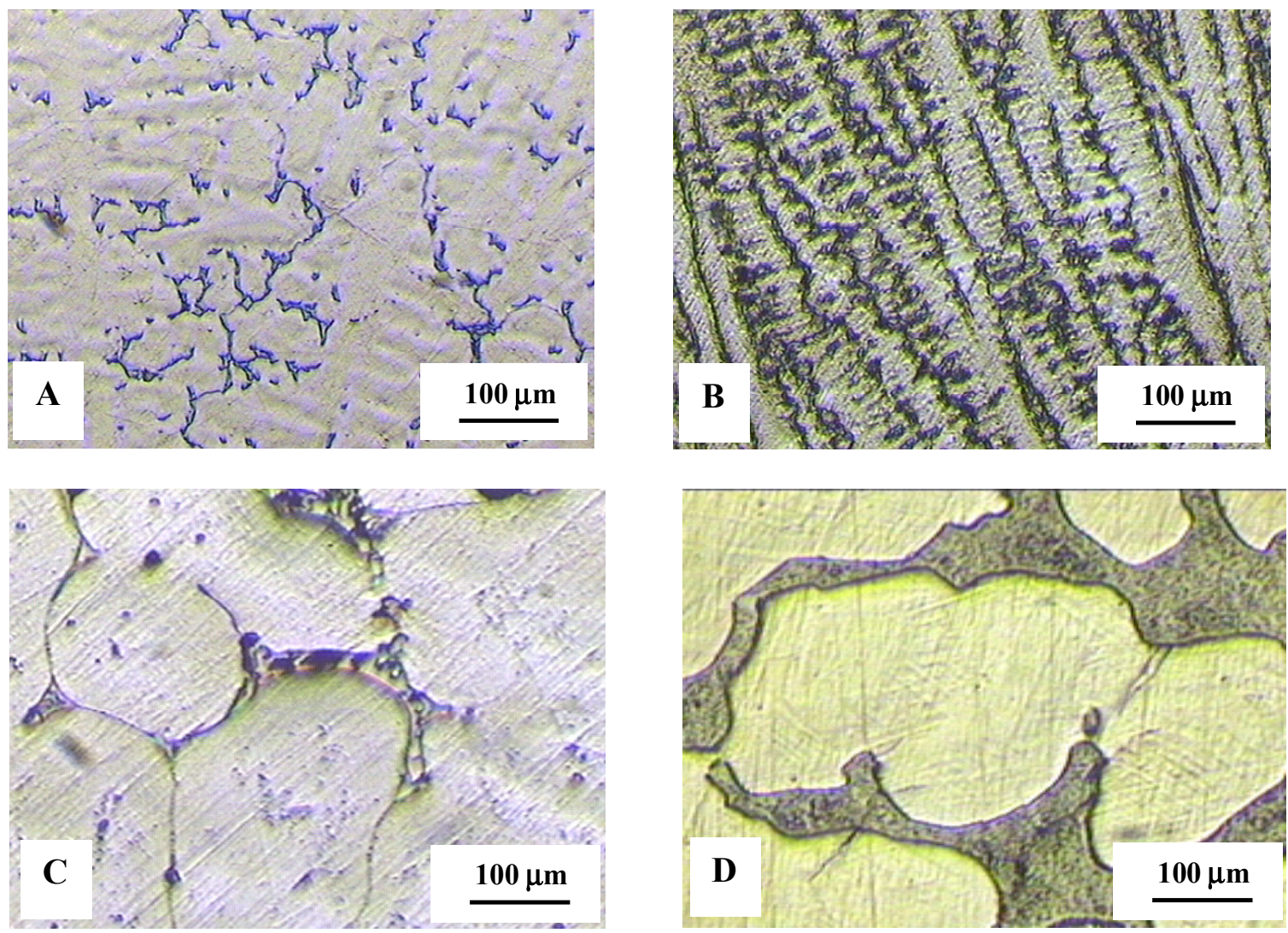

Fig. (1). Optical microscopy images of specimens: (A) Heraenium alloy,

environment takes place. The effect of this interaction may be manifested as: (1) release of soluble metallic ions into the oral environment; (2) formation of corrosion products on the alloy surface; or (3) a combination of both. These effects, depending on the altered alloy surface and/or the nature of released metallic ions, may trigger adverse biological reactions such as allergy [27].

For a specific environment, corrosion depends on the structure and composition of the alloy. The alloys of the present study have different compositions and microstructure.

The intra-orally temperature widely fluctuates because of ingestion of hot or cold food and beverage. Furthermore, different areas of oral cavity exhibited different temperature. Nevertheless, it can be reasonably approximated in experimental settings between $35{ }^{\circ} \mathrm{C}$ and $37{ }^{\circ} \mathrm{C}$ if we considered the environmental temperature as $25^{\circ} \mathrm{C}$ [28].

\subsubsection{Open Circuit Potential, $E_{O C}$}

The metals immersed in an electrolytic environment generate an electric potential which stabilises to a stationary value after a period of immersion.

Fig. (2) shows the curves of the open circuite potentials versus time for the four alloys in test solution.

After 1 hour of immersion $\mathrm{E}_{\mathrm{OC}}$ displacement towards positive potentials was noticed in Fig. (2). This increase seems to be related to the thickening of the oxide film improving its corrosion protection ability.

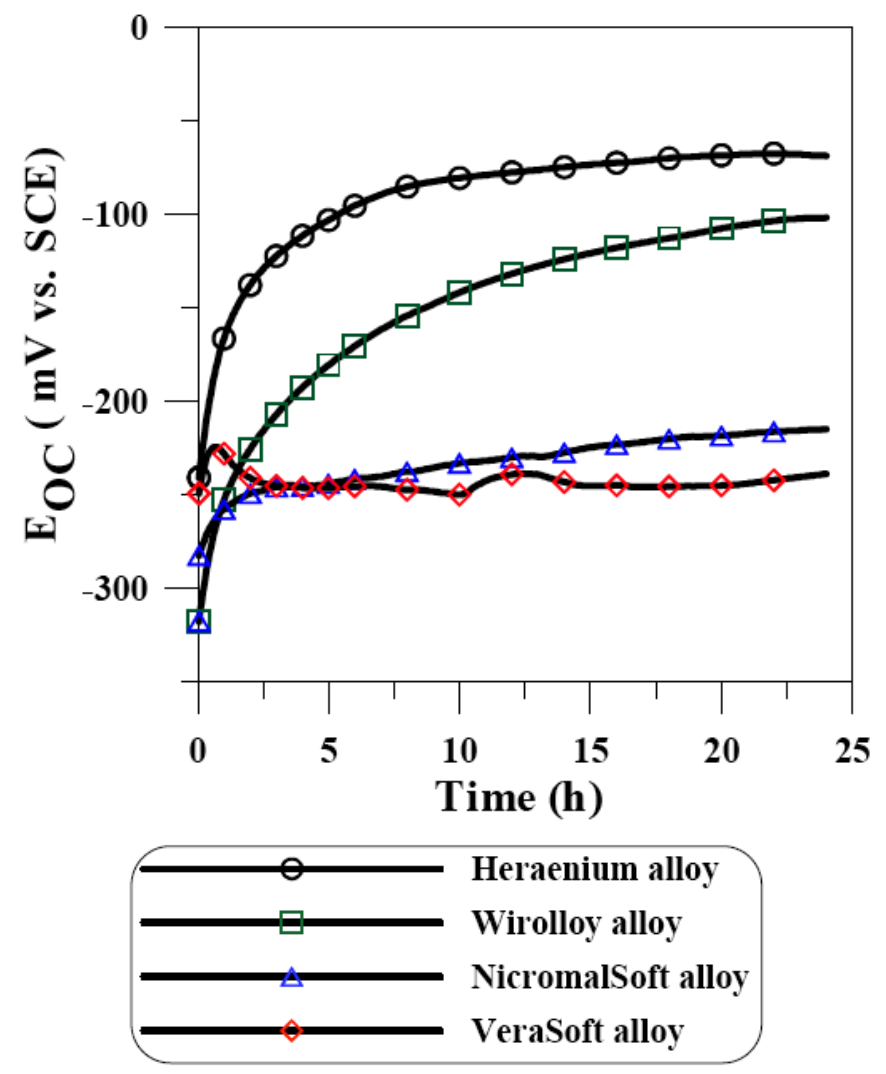

Fig. (2). Open Circuit Potential $\left(\mathrm{E}_{\mathrm{OC}}\right)$ vs time for NiCr-based alloys. Testing medium was $0.1 \mathrm{M} \mathrm{NaCl}$ solutions and temperature was $25^{\circ} \mathrm{C}$. 
Specimens: Heraenium, Wirolloy and NicromalSoft of solution treated did not exhibit potential drops associated with surface activation during 24 hours exposure test solution. This kind of behavior suggests that the air-formed native oxide is thermodynamically resistant at chemical dissolution in $0.1 \mathrm{M} \mathrm{NaCl}$ solutions.

The disruptions noted for the curve of VeraSoft alloy are difficult to interpret, but they probably came from surface phenomenon such as depassivation-passivation in the system. The open circuit potential of all the alloys is summarized in Table 2.

The highest $\mathrm{E}_{\mathrm{OC}}$ was found for Heraenium alloy followed by Wirolloy alloy and NicromalSoft alloy.

Table 2. The Open Circuit Potential Values: Initial and After 24 Hours from Alloys Samples Immersion in 0.1 M NaCI Solution

\begin{tabular}{|c|c|c|c|}
\hline \multirow{2}{*}{ Alloy } & \multicolumn{3}{|c|}{ Open Circuit Potential, $\mathbf{E}_{\text {OC }}(\mathbf{m V})$} \\
\cline { 2 - 4 } & Initial & After 1 Hour & After 24 Hours \\
\hline \hline Heraenium & $-241 \pm 15$ & $-166 \pm 8$ & $-69 \pm 4$ \\
\hline Wirolloy & $-318 \pm 25$ & $-235 \pm 10$ & $-102 \pm 5$ \\
\hline NicromalSoft & $-283 \pm 20$ & $-258 \pm 12$ & $-215 \pm 10$ \\
\hline VeraSoft & $-250 \pm 18$ & $-228 \pm 12$ & $-239 \pm 12$ \\
\hline
\end{tabular}

\subsubsection{Potentiodynamic Polarization}

Plots in a semi-logarithmic version between $-600 \mathrm{mV}$ and $+1200 \mathrm{mV} \mathrm{SCE}$ of the four NiCr-based alloys after 24 hours in $0.1 \mathrm{M} \mathrm{NaCl}$ solutions are displayed in Fig. (3). Standard techniques were used to extract zero current potential (ZCP) and corrosion current $\left(i_{\text {corr }}\right)$ values from the potentiodynamic polarization plots. The average values $b_{a}, b_{c}, Z C P$ and $i_{\text {corr }}$ from polarization curves determined by the PowerCorr program (PAR, USA) are presented in Table 3.

An alloy that prone to passivity will have the value of $b_{a}$ greater than $b_{c}$, while an alloy that corrodes will have $b_{a}$ less than $b_{c}$ [29]. Values of $b_{c}$ amount to $120 \pm 10 \mathrm{mV} /$ div (Tafellike behaviour). The high value of $b_{a}$ in comparison with the values of $b_{c}$ for all the four alloys indicates an anodic control in the corrosion process. The control implies the existence of a passive layer on the material's surface. The two Tafel slopes intercept at the point of the coordinates $\left(Z C P, i_{\text {corr }}\right)$. In all cases the values determined for the $\mathrm{ZCP}$, are smaller than those corresponding to $\mathrm{E}_{\mathrm{OC}}$ (Table 2). The variation is probably due to depassivation phenomena on the surface during cathodic scanning. The corrosion currents for all the alloys were of the same order of magnitude $\left(\mathrm{nA} / \mathrm{cm}^{2}\right)$.
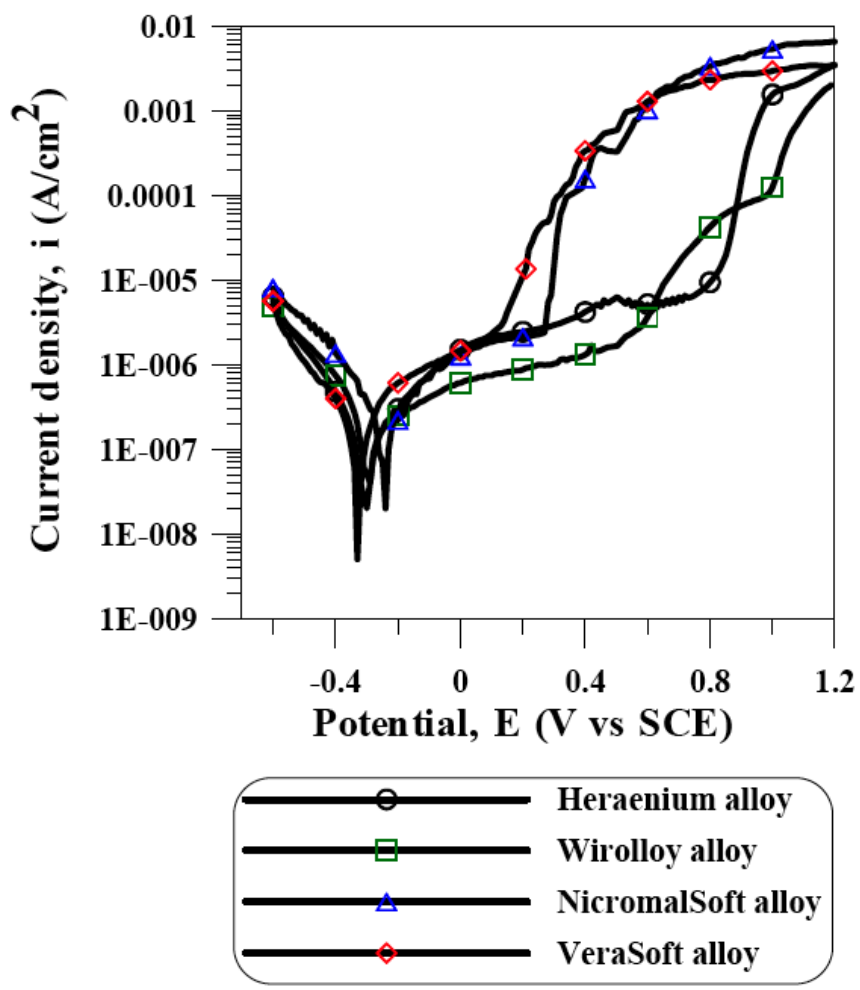

Fig. (3). Potentiodynamic polarisation curves of NiCr-based alloy tested after 24 hours maintained in $0.1 \mathrm{M} \mathrm{NaCl}$ solutions, on semilogarithmic axes.

According to Fig. (3), the polarisation curves can be placed into two groups. The first group with Heraenium and Wirolloy alloys shows the best behaviour. In the anodic area (from 300 to $600 \mathrm{mV}$ ) there are anodic currents of $\mu \mathrm{A}$ order. The second group with VeraSoft and NicromalSoft alloys shows the worst behaviour with anodic currents of $\mathrm{mA}$ order in the anodic area from 300 to $600 \mathrm{mV}$.

All materials translated directly into a stable passive behaviour from the "Tafel region" without exhibiting a traditional active-passive transition. It has been reported that $\mathrm{Cr}$ containing Ni-based alloys in acid solutions become passive by anodic polarization [30].

Fig. (4) shows in linear representation the part of the polarisation curve for all the four alloys after 24 hours in test solution, in the scale of anodic currents comprising between 0 and $500 \mu \mathrm{A} / \mathrm{cm}^{2}$. This help to visualise the breakdown potential $\mathrm{E}_{\mathrm{bd}}$, another electrochemical parameter, which

Table 3. The Main Parameters of the Corrosion Process Measured and Calculated for the Various NiCr-Based Alloys Maintained 24 Hours in $0.1 \mathrm{M}$ NaCl Solution $\left(25^{\circ} \mathrm{C}\right)$

\begin{tabular}{|c|c|c|c|c|c|c|c|}
\hline Alloy & $\mathrm{ZCP}(\mathrm{mV})$ & $b_{a}(m V / d i v)$ & $b_{c}(m V / d i v)$ & $\mathbf{i}_{\text {corr }}\left(\mathbf{n A} / \mathbf{c m}^{2}\right)$ & $\mathbf{i}_{\text {pass }}\left(\boldsymbol{\mu} \mathbf{A} / \mathbf{c m}^{2}\right)$ & $E_{b d}(m V)$ & PRE \\
\hline Heraenium & $-300 \pm 15$ & $155 \pm 10$ & $125 \pm 5$ & $129 \pm 7$ & $3.2 \pm 0.2$ & $800 \pm 10$ & 57 \\
\hline NicromalSoft & $-240 \pm 10$ & $155 \pm 10$ & $130 \pm 5$ & $158 \pm 5$ & $2.8 \pm 0.2$ & $280 \pm 5$ & 14.5 \\
\hline VeraSoft & $-340 \pm 20$ & $140 \pm 10$ & $125 \pm 5$ & $177 \pm 5$ & $3.1 \pm 0.2$ & $190 \pm 5$ & 17.8 \\
\hline
\end{tabular}


characterises the corrosion behaviour of the alloys. The potential range situated between the $\mathrm{ZCP}$ and $\mathrm{E}_{\mathrm{br}}$ represents the passivity zone in which corrosion is weak or even insignificant. Table 3 presents the values of the breakdown potential.
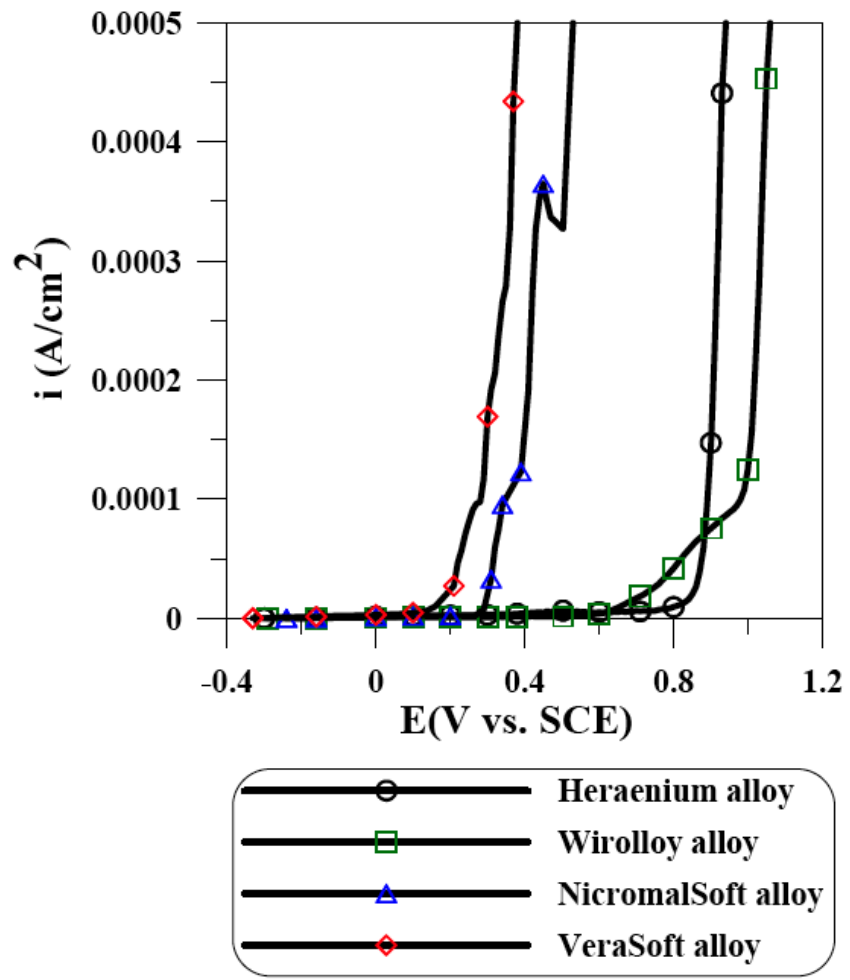

Fig. (4). Potentiodynamic polarisation curves presented on linear axes in order to reveal the breakdown potential for NiCr-based alloy after 24 hours in $0.1 \mathrm{M} \mathrm{NaCl}$ solution.

According to the values of $\mathrm{E}_{\mathrm{bd}}$, quite different corrosion behaviour can be attributed to various NiCr-based alloys. $\mathrm{E}_{\mathrm{bd}}$ of VeraSoft alloy is around $200 \mathrm{mV}$. The passive zone is around $500 \mathrm{mV}\left(\mathrm{E}_{\mathrm{bd}}-\mathrm{ZCP}\right)$, implying the corrosion start from $200 \mathrm{mV}$. The NicromalSoft presents a similar behaviour, with $\mathrm{E}_{\mathrm{bd}}$ smaller, around $300 \mathrm{mV}$ and the passive zone around $500 \mathrm{mV}$. The passive zone of the Wirolloy alloy extends up to $900 \mathrm{mV}$. $\mathrm{E}_{\mathrm{bd}}$ of Heraenium alloy is around 800 $\mathrm{mV}$ and the passive zone is very large, around $1100 \mathrm{mV}$.

A low $\mathrm{Cr}$ and Mo content in the NiCr-based alloys are associated with a high corrosion rate and susceptibility to accelerated corrosion processes [30]. In this study, the presence of larger passive range for the Heraenium and Wirolloy specimens with respect to the other two NiCr-based alloys was ascribed mainly to a higher amount of $\mathrm{Cr}$ and $\mathrm{Mo}$ in the chemical composition of specimens.

In this table: ZCP - zero current potential, $b_{c}$ and $b_{a}-$ Tafel slopes, $\mathrm{i}_{\text {corr }}-$ corrosion current density, $\mathrm{E}_{\mathrm{bd}}-$ breakdown potential, $i_{\text {pass }}$ - passive current density.

Passive current density ( $i_{\text {pass }}$ ) was also determined from the potentiodynamic anodic diagram of each specimen in test solution.

Passive current density ( $\mathrm{i}_{\text {pass }}$ ) is obtained around the middle of the passive range as listed in Table 3 . The passive current densities of the samples investigated were of the same order of magnitude (about $1-3 \mu \mathrm{A} / \mathrm{cm}^{2}$ ).
Fig. (5) shows the surface micrographs of alloys after the electrochemical measurements. The microscopic analysis indicated the behavior of Heraenium alloy to be different from the three other alloys which exhibited pitting corrosion.

The analysis of Fig. (5) indicates the appearance of corrosion points at the surface of Wirolloy, VeraSoft and NicromalSoft alloys and the development of a uniform corrosion process in case of Heraenium alloy.

It has been reported that the content of $\mathrm{Cr}$ and Mo plays an important role in the corrosion resistance of Ni-based dental alloy [6-8, 31-33]. Also, Matkovic et al. indicates that only CoCrMo alloys with dentritic solidification microstructure have good corrosion characteristics in artificial saliva [34]. The presence of higher $\mathrm{Cr}(24 \%)$ and Mo $(10 \%)$ contents in the Heraenium alloys promoted immunity to pitting corrosion. The specimens without Mo contents are susceptible to pitting corrosion. On the other hand, the Wirolloy alloy with 3\% Mo content still was susceptible to pitting corrosion even through a high $\mathrm{Cr}$ content was $23 \%$. For Fe-Ni-Cr-Mo stainless steel, the relative effectiveness of $\mathrm{Cr}$ and Mo content on pitting or crevice corrosion usually can be assessed qualitatively by pitting resistance equivalent (PRE), which is represented by the empirical equation [35]:

$\mathrm{PRE}=\% \mathrm{Cr}+3.3 \% \mathrm{Mo}$

A PRE above 38 is supposed to provide good resistance to pitting corrosion in a $\mathrm{Cl}^{-}$ion containing environment. The $\mathrm{Ni}-\mathrm{Cr}$-Mo casting alloy is pitting resistant in acidic artificial saliva when the PRE value increases up to around 49 [35]. In this study, according to the PRE equation mentioned above, the PRE values for the pitting-resistant Heraenium alloy were 57. The other three NiCr-based alloys, which were susceptible to pitting corrosion, had PRE values between 14.5 and 32.9 .

\subsubsection{Electrochemical Impedance Spectroscopy}

In a complementary study, electrochemical impedance spectroscopy (EIS) was used to investigate the corrosion resistance of NiCr-based alloys.

The experimental impedance data obtained, at $\mathrm{E}_{\mathrm{OC}}$, with the alloys immersed for different periods of time are presented as Bode plots in Figs. (6-9).

From the Bode spectra it is possible to indicate the presence of a compact passive film if: (a) the phase angle is close to $90^{\circ}$ over a wide frequency range and (b) if the spectrum shows linear portions at intermediate frequency.

The impedance $(Z)$ of all alloys increases with the time of electrode immersion. All the spectra show that in a higher frequency region, $\mathrm{lg} Z \mathrm{Zmod}$ tends to become constant. This is a typical response for the resistive behaviour and corresponds to the solution resistance, $\mathrm{R}_{\mathrm{sol}}$. In the medium frequency range, a linear relationship between $1 \mathrm{~g} Z \mathrm{Zmod}$ and $\lg$ frequency is observed for all the samples, but with different slopes (always less than -1) and phase angle maxim (less than $-90^{\circ}$ ), indicating that the passive films were not fully capacitive.

Fig. (6) shows Bode plots for Heraenium alloy in $0.1 \mathrm{M}$ $\mathrm{NaCl}$ solutions. At intermediate frequency the phase angles shifted to $-70^{\circ}$ for the alloy maintained 1 minute in test 

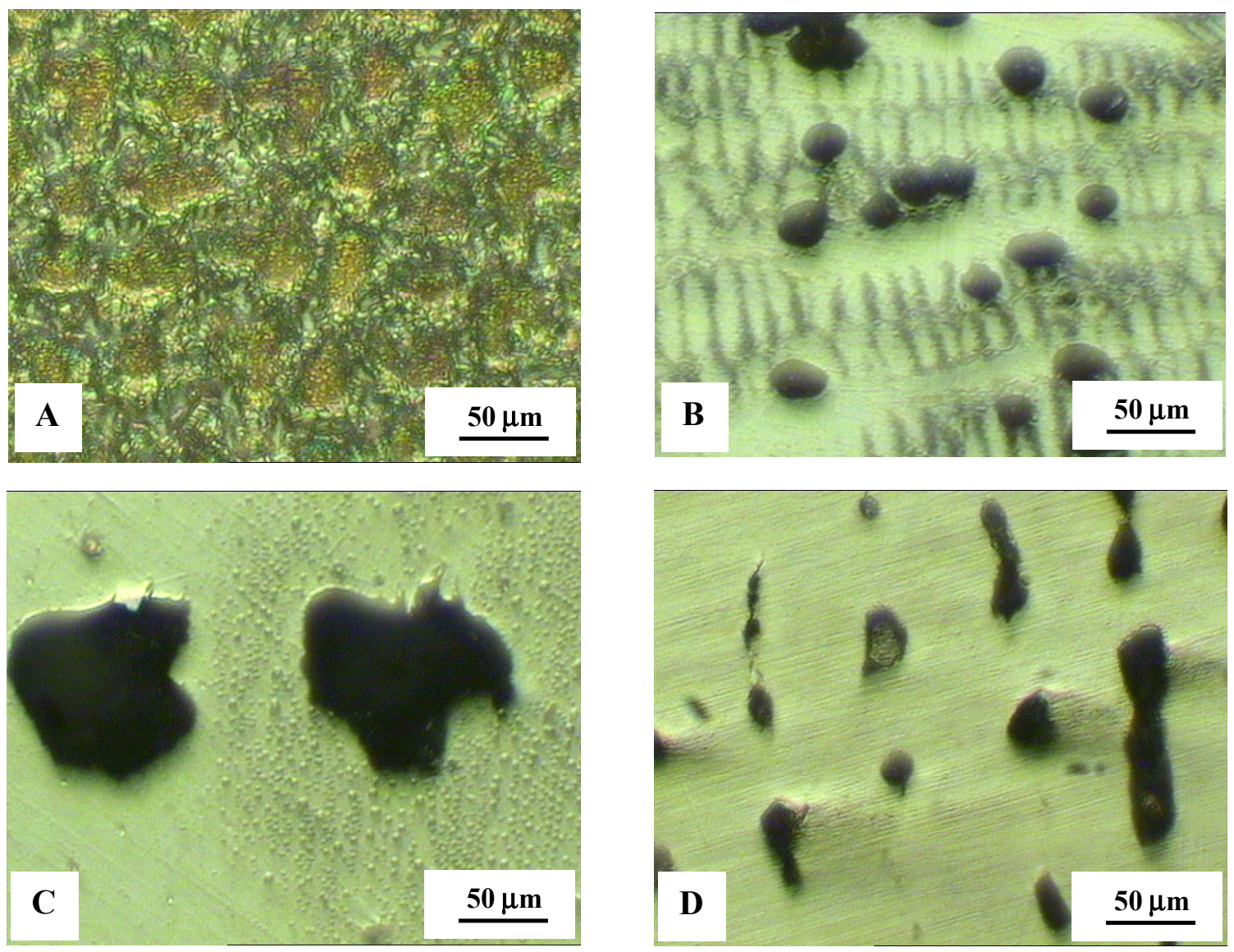

Fig. (5). Surface attack morphology: (A)-Heraenium alloy, (B)-Wirolloy alloy, (C)-NicromalSoft alloy, (D)-VeraSoft alloy.

solution and increases in time up to $-80^{\circ}$ for alloy maintained 24 hours in test solution and remain constant over a wide frequency range, indicating a capacitive response of this alloy.

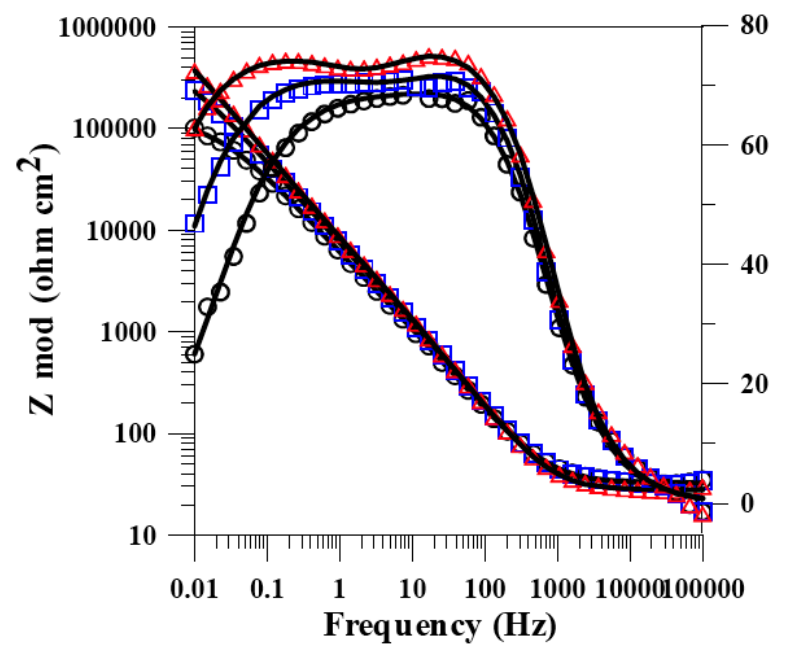

\begin{tabular}{cl}
\hline 0 & 1 minute (experimental) \\
$\square$ & 1 hour (experimental) \\
$\Delta$ & 1 day (experimental) \\
\hline
\end{tabular}

Fig. (6). Impedance spectra of Heraenium alloy maintained different time periods in test solution measured at $\mathrm{E}_{\mathrm{OC}}$.

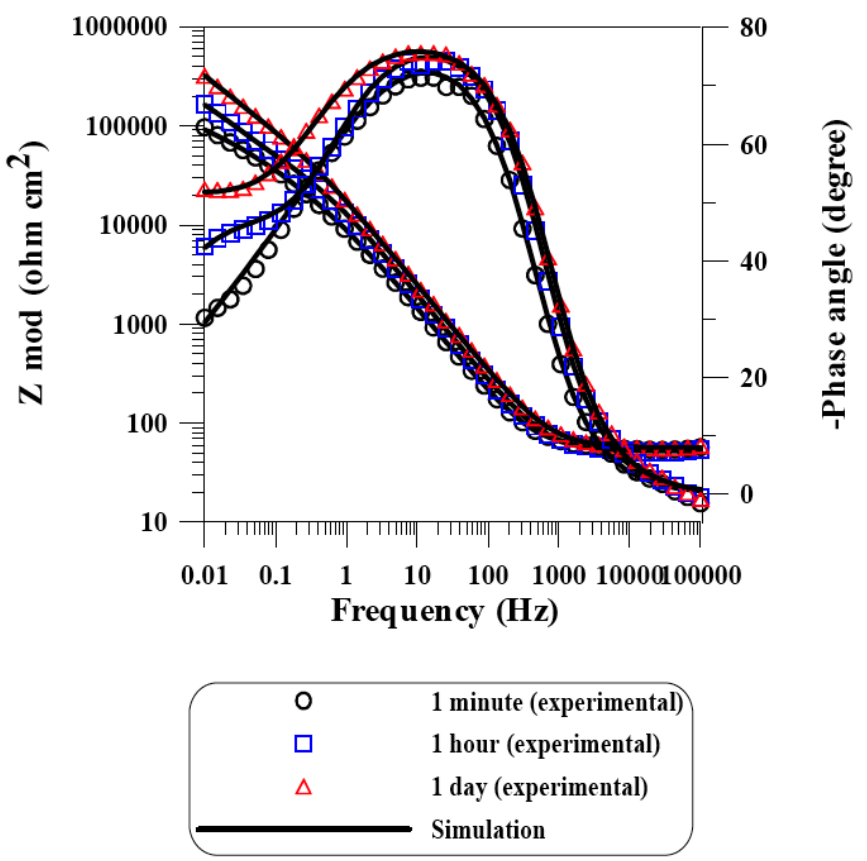

Fig. (7). Bode plots of the Wirolloy alloy for various exposure times to the test solution measured at $\mathrm{E}_{\mathrm{OC}}$.

Impedance spectra for Wirolloy alloy in $0.1 \mathrm{M} \mathrm{NaCl}$ solutions, represented as Bode plots are shown in Fig. (7). The impedance spectra found for the Wirolloy alloy exhibited a capacitive response illustrated by a phase angle close to $-80^{\circ}$ in medium frequency range. 

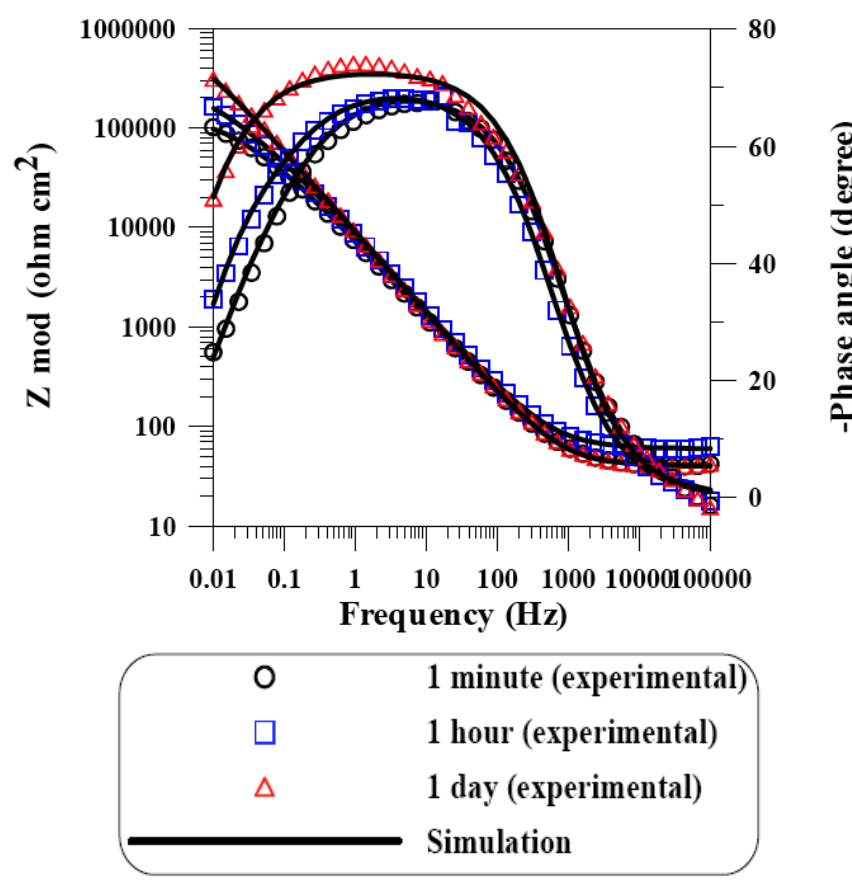

Fig. (8). Impedance spectra of NicromalSoft alloy maintained different time periods in test solution measured at $\mathrm{E}_{\mathrm{OC}}$.

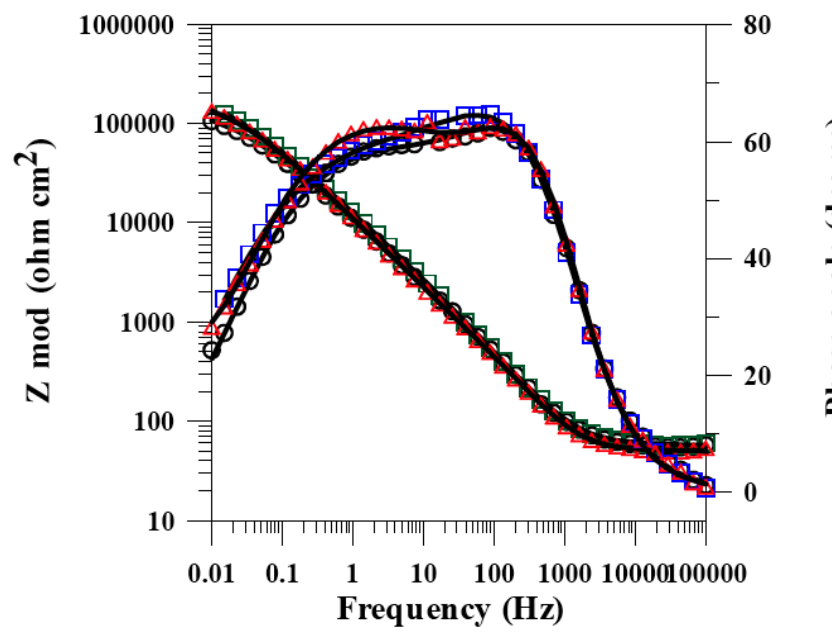

\begin{tabular}{cl}
\hline 0 & 1 minute (experimental) \\
$\square$ & 1 hour (experimental) \\
$\Delta$ & 1 day (experimental) \\
\hline
\end{tabular}

Fig. (9). Impedance spectra of VeraSoft alloy maintained different time periods in $0.1 \mathrm{M} \mathrm{NaCl}$ solutions measured at $\mathrm{E}_{\mathrm{OC}}$.

The Bode plots for the NicromalSoft alloy in $0.1 \mathrm{M} \mathrm{NaCl}$ solutions are shown in Fig. (8). A capacitive behaviour, typical for the passive materials is indicated by medium to low frequency by phase angle approaching $-80^{\circ}$, suggesting that a stable film is formed on the tested alloy in the electrolyte used.

The impedance spectra found for the VeraSoft alloy (Fig. 9) exhibited a near capacitive response illustrated by a phase angle close to $-70^{\circ}$ in medium frequency range.

For the interpretation of the electrochemical behaviour of a system from EIS spectra, it is necessary an appropriate physical model of the electrochemical reactions occurred on the electrodes. Because the electrochemical cell presents impedance at a small sinusoidal excitation it can be represented by an equivalent circuit (EC). The EC consists of various arrangements of resistances, capacitors and other circuit elements, and provides the most relevant corrosion parameters applicable to the substrate/electrolyte system. The usual guidelines for the selection of the best-fit EC were followed:

- a minimum number of circuit elements are employed,

- $\quad$ the $\chi^{2}$ error was suitably low $\left(\chi^{2}<10^{-4}\right)$, and the error associated with each element was up to $5 \%$.

The EC that satisfied the above criteria and presented in Fig. (10) was used to fit the experimental data and the resultant parameters are given in Table 4. Instead of pure capacitors, constant phase elements (CPE) were introduced in the fitting procedure to obtain good agreement between the simulated and experimental data. The impedance of CPE is defined as $Z_{C P E}=\frac{1}{Q(j \omega)^{n}}$ where $\mathrm{Q}$ is the combination of properties related to both the surfaces and electro active species independent of frequency; $\omega$ is the angular frequency and $j$ is imaginary number $\left(j^{2}=-1\right), \mathrm{n}$ is related to a slope of the $\mathrm{lg}$ $\mathrm{Z} v s \mathrm{lg}$ frequency Bode-plots and usually is in the range 0.5 and 1 . When the value of $n$ is equal to 1 , the CPE describes an ideal capacitor with $\mathrm{Q}$ equal to the capacitance (C). For $0.5<\mathrm{n}<1$ the CPE describes a distribution of dielectric relaxation times in frequency space, and when $\mathrm{n}$ is equal to 0.5 the CPE represents a Warburg impedance with diffusional character.

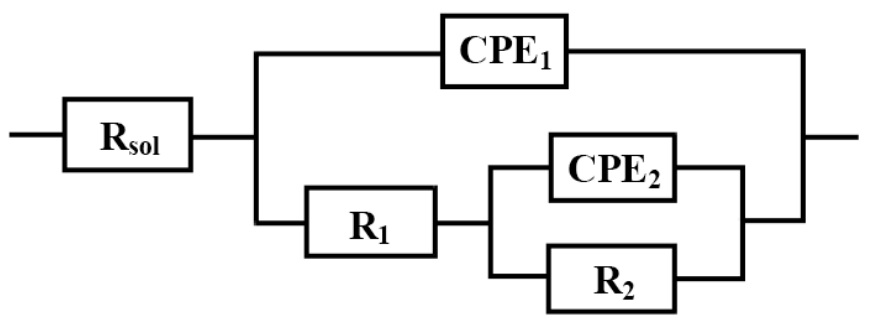

Fig. (10). Equivalent circuit (EC) used in the generation of simulated data.

In the Figs. (6-9), the experimental data are shown as individual points, while the theoretical spectra resulted from the fits with a relevant EC model are shown as lines.

The physical meaning given to the circuit is the association of the film/electrolyte interface $\left(\mathrm{R}_{1} \mathrm{CPE}_{1}\right)$ with the passive film itself $\left(\mathrm{R}_{2} \mathrm{CPE}_{2}\right)$. The time constant at high frequencies is originated from the $\mathrm{R}_{1} \mathrm{CPE}_{1}$ combination while the one at low frequencies initiated from the $\mathrm{R}_{2} \mathrm{CPE}_{2}$ combination. $\mathrm{R}_{1}$ representing the charge transfer resistance and $\mathrm{CPE}_{1}$ the double layer capacitance are shown by the high value of the $\mathrm{n}_{1}$ exponent. The double layer capacitances for all the samples are typical for the $\mathrm{C}_{\mathrm{dl}}$ of the passive oxide layers [36-39]. The same value for cell resistance, $R_{\text {sol }}$, equals $35 \pm 5 \Omega$, was observed for all of the specimens indifferent the time of immersion and it wasn't inserted in Table 4. 
Table 4. Impedance Parameters of NiCr-Based Alloys in $0.1 \mathrm{M}$ NaCl Solutions at $\mathrm{E}_{\mathrm{OC}}$

\begin{tabular}{|c|c|c|c|c|c|c|c|}
\hline Alloy & $R_{1}\left(k \Omega \mathrm{cm}^{2}\right)$ & $10^{5} \mathrm{CPE}_{1}\left(\mathrm{~S} \mathrm{~cm}^{-2} \mathrm{~s}^{\mathrm{n}}\right)$ & $\mathbf{n}_{1}$ & $\mathbf{R}_{2}\left(\mathbf{k} \Omega \mathbf{c m}^{2}\right)$ & $10^{5} \mathrm{CPE}_{2}\left(\mathrm{~S} \mathrm{~cm}^{-2} \mathrm{~s}^{\mathrm{n}}\right)$ & $\mathbf{n}_{2}$ & $i_{\text {corr }}\left(\mathbf{n A} / \mathbf{c m}^{2}\right)$ \\
\hline & \multicolumn{7}{|c|}{ The Alloys Maintained for 1 Minute in Test Solution } \\
\hline Wirolloy & $15 \pm 2$ & $1.9 \pm 0.1$ & 0.8 & $150 \pm 5$ & $2.7 \pm 0.1$ & 0.55 & - \\
\hline NicromalSoft & $4 \pm 1$ & $6.5 \pm 0.2$ & 0.83 & $95 \pm 4$ & $5.1 \pm 0.2$ & 0.58 & - \\
\hline VeraSoft & \multicolumn{7}{|c|}{ The Alloys Maintained for 1 Hour in Test Solution } \\
\hline Heraenium & $16 \pm 2$ & $2.1 \pm 0.1$ & 0.87 & $191 \pm 5$ & $1 \pm 0.1$ & 0.71 & - \\
\hline Wirolloy & $37 \pm 2$ & $1.3 \pm 0.1$ & 0.87 & $284 \pm 7$ & $2.6 \pm 0.1$ & 0.65 & - \\
\hline NicromalSoft & $15 \pm 2$ & $2.2 \pm 0.1$ & 0.87 & $140 \pm 4$ & $2.7 \pm 0.1$ & 0.75 & - \\
\hline Wirolloy & $32 \pm 3$ & $1.1 \pm 0.1$ & 0.87 & $320 \pm 6$ & $1.2 \pm 0.1$ & 0.8 & $90 \pm 4$ \\
\hline NicromalSoft & $25 \pm 2$ & $1.5 \pm 0.1$ & 0.89 & $305 \pm 6$ & $2.2 \pm 0.1$ & 0.81 & $93 \pm 5$ \\
\hline VeraSoft & $11 \pm 2$ & $2.1 \pm 0.1$ & 0.87 & $165 \pm 4$ & $1.8 \pm 0.1$ & 0.78 & $161 \pm 7$ \\
\hline
\end{tabular}

Although the actual value of the dielectric constant within the passive film is difficult to estimate, a change of $\mathrm{CPE}_{2}$ can be used as indicator for the changes in the passive film thickness. Assuming the dielectric constant does not change with the different parameters under investigation; the reciprocal capacitance of the passive film, $1 / \mathrm{CPE}_{2}$, is directly proportional to the thickness of the passive film. The resistance, $\mathrm{R}_{2}$, and the thickness, $1 / \mathrm{CPE}_{2}$, of the passive film increase with the immersion time indicating a continuous growth of the passive film in time until a steady state is attained.

The polarization resistance $\left(R_{p}\right)$ of the NiCr-based alloys equals the sum of the $R_{1}\left(R_{c t}\right)$ and the passive film resistance, $R_{2}$. $R_{p}$ allows a quantitative analysis based on the specific magnitudes of the corrosion rate. It is therefore representative of the degree of protection of the passive layer at the alloy surface. The more the value of polarization resistance increases, the more the alloy will resist corrosion.

From the Stern-Geary equation [39]:

$i_{\text {corr }}=\frac{b_{a} b_{c}}{2.3 R_{p}\left(b_{a}+b_{c}\right)}=\frac{B}{R_{p}}$

where: $b_{a}$ and $b_{c}$ are the Tafel slopes for the partial anodic and cathodic processes, respectively and B is a constant:

$\mathrm{B}=\frac{\mathrm{b}_{\mathrm{a}} \mathrm{b}_{\mathrm{c}}}{2.3\left(\mathrm{~b}_{\mathrm{a}}+\mathrm{b}_{\mathrm{c}}\right)}$

The polarisation resistance $\left(\mathrm{R}_{\mathrm{p}}\right)$ of the alloys are largest, of the same order of magnitude and increase with the immersion time. For highly corrosion resistance materials the $\mathrm{R}_{\mathrm{p}}$ may even reach $1 \mathrm{M} \Omega \mathrm{cm}^{2}$ [26]. For surgical implants with very low corrosion rates, the $\mathrm{R}_{\mathrm{p}}$ may reach $1 \mathrm{M} \Omega \mathrm{cm}^{2}$ [40]. In $0.9 \% \mathrm{NaCl}$ solution, the $\mathrm{R}_{\mathrm{p}}$ of commercially pure (CP) titanium and $\mathrm{CoCr}$ alloy is around 0.7 and $0.003 \mathrm{M} \Omega \mathrm{cm}^{2}$, respectively [41]. Pan et al. [42] found that the $\mathrm{R}_{\mathrm{p}}$ of titanium in phosphate-buffered saline (PBS) solution is around $1 \mathrm{M} \Omega \mathrm{cm}^{2}$. Huang [43] also claimed that the $\mathrm{R}_{\mathrm{p}}$ of $\mathrm{CP}$ titanium in acidic artificial saliva $\left(\mathrm{pH} \mathrm{5)}\right.$ is close to $1 \mathrm{M} \Omega \mathrm{cm}^{2}$. Therefore, the passive films formed on various $\mathrm{NiCr}$-based alloys used in this study all exhibited an acceptable corrosion resistance in the $0.1 \mathrm{M} \mathrm{NaCl}$ solutions referring to the above-mentioned literature.

The corrosion currents obtained from the Stern-Geary equation for the NiCr-based alloys maintained for 24 hours in $0.1 \mathrm{M} \mathrm{NaCl}$ solutions are in agreement with the polarization data.

For all the alloys maintained 1 minute in $0.1 \mathrm{M} \mathrm{NaCl}$ solutions the values of $\mathrm{n}_{2}$ are small, in the range 0.55-0.6 indicating the presence of a diffusion process within the interfacial layer of the solution. Such a diffusion process is indicating a reversible dissolution process that is the passive film formation under open circuit condition proceeds through a dissolution-precipitation mechanism [44]. The values of $n_{2}$ increase with the immersion time supposing that the roughness of the passive layer is decreasing [45].

\section{CONCLUSIONS}

In the present study, the electrochemical behavior of four NiCr-based alloys was evaluated using electrochemical techniques.

Very low corrosion current densities, typical of passive materials, were obtained for all the samples tested in $0.1 \mathrm{M} \mathrm{NaCl}$ solutions.

For VeraSoft and NicromalSoft alloys low and dangerous breakdown potential values may be recorded. Over the surface of the Heraenium alloy a uniform corrosion appears, while in case of the Wirolloy, VeraSoft and NicromalSoft alloys surface a pitting corrosion is developed. The $\mathrm{Cr}$ and Mo contents play a significant role in corrosion resistance: Heraenium alloy with 
high $\mathrm{Cr}$ and Mo content exhibit a much wider passivation range and a better resistance to pitting corrosion.

The EIS results show that NiCr-based alloys exhibit passivity at open circuit potential. For all the samples the polarization resistance are increasing with the immersion time because of the surface passivation. The Heraenium and Wirolloy alloys with dendrites microstructure show the best electrochemical behaviour in $0.1 \mathrm{M} \mathrm{NaCl}$ solutions.

\section{REFERENCES}

[1] Staiger MP, Pietak AM, Huadmai J, Dias G. Magnesium and its alloys as orthopedic biomaterials: A review. Biomaterials 2006; 27(9): 172834.

[2] Wapner KL. Implications of metallic corrosion in total knee orthoplasty. Clin Orthop Relat Res 1991; 271: 12-20.

[3] Cortada M, Giner LL, Costa S, Gil FJ, Rodrigez, D, Planell JA. Galvanic corrosion behavior of titanium implants coupled to dental alloys. J Mater Sci Mater Med 2005; 11(5): 2000.

[4] Venugopalan R, Lucas LC. Evaluation of restorative and implant alloys galvanically coupled to titanium. Dent Mater 1998; 14(3): 165-72.

[5] Leinfelder KF. New developments in resin restorative system. J Am Dent Assoc 1997; 128: 573-581.

[6] Friend WZ. Corrosion of nickel and nickel-based alloys. New York: John Wiley and Sons 1980.

[7] Geis-Gerstorfer J, Greener EH. Effect of Mo content and $\mathrm{pH}$ value on the corrosion behavior of Ni-20Cr-Mo dental alloys. Dtsch Zahnarztl Z 1989; 44(11): 863-6.

[8] Geis-Gerstorfer J, Weber H. In vitro corrosion behaviour of four $\mathrm{Ni}-\mathrm{Cr}$ dental alloys in lactic acid and sodium chloride solutions. Dent Mater 1987; 3 (6): 289-95.

[9] Roach MD, Wolan JT, Parsell DE, Bumgardner JD. Use of x-ray photoelectron spectroscopy and cyclic polarization to evaluate the corrosion behaviour of six nickel-chromium alloys before and after porcelain-fused-to-metal firing. J Prosthet Dent 2000; 84(6): 623-34.

[10] Huang HH. Surface characterization of passive film on NiCr-based dental casting alloys. Biomaterials 2003; 24(9): 1575-1582.

[11] Wylie CM, Shelton RM, Fleming GJP, Davenport AJ. Corrosion of nickel-based casting alloys. Dent Mater 2007; 23: 714-23.

[12] Assis S L, Wolynec S, Costa I. Corrosion characterization of titanium alloys by electrochemical techniques. Electrochim Acta 2006; 51: 181519.

[13] Choubey A, Balasubramaniam R, Basu B. Effect of replacement of V by $\mathrm{Nb}$ and $\mathrm{Fe}$ on the electrochemical and corrosion behavior of Ti-6Al$4 \mathrm{~V}$ in simulated physiological environment. J Alloys Compd 2004; 381 (1-2): 288-94.

[14] López MF, Gutiérrez A, Jiménez JA. In vitro corrosión behavior of titanium alloys without vanadium. Electrochim Acta 2002; 47: 1359-64.

[15] Zheng YF, Wang BL, Wang JG, Li C, Zhao LC. Corrosion behavior of $\mathrm{Ti}-\mathrm{Nb}-\mathrm{Sn}$ shape memory alloys in different simulated body solutions. Mater Sci Eng A 2006; 438: 891-95.

[16] Fathi MH, Salehi M, Saatchi A, Mortazavi V, Moosavi SB. In vitro corrosion behavior of bioceramic metallic, and bioceramic-metallic coated stainless steel dental implants. Dent Mater 2003; 19(3): 188-98.

[17] Schmalz G, Garhammer P. Biologic interactions of dental cast alloys with oral tissue. Dent Mater 2002; 18: 396-6.

[18] Wataha JC. Biocompatibility of dental casting alloys : a review. J Prosthet Dent 2000 ; 83: 223-234.

[19] Mjor, IA, Christensen GJ. Assessment of local side effects of casting alloys. Quintessence Int 1993; 5(24): 343-51.

[20] Bumgardner JD, Lucas LC. Cellular response to metallic ions released from nickel- chromium dental alloys. J Dent Res 1995; 74(8): 1521-27.

[21] Bumgardner JD, Doeller J, Lucas LC. Effect of nickel based dental casting alloys on fibroblast metabolism and ultrastructural organization. J Biomed Mater Res 1995: 29(5): 611-7.
[22] Sectos JC, Babei-Mahani A, Di Silvio L, Mjor IA. The safety of nickel containing dental alloys. Dent Mater 2006; 22(12): 1163-68.

[23] Mareci D, Ungureanu G, Aelenei N, Chelariu, R, Mirza-Rosca JC. EIS diagnosis of some dental alloys in artificial saliva. J Environ Eng Manage 2007; 6(4): 313-17.

[24] Mareci D, Ungureanu G, Aelenei N, Mirza-Rosca JC. Comparative corrosion study of non-precious Ni/Cr-based soft alloys in view of dental applications. J Environ Eng Manage 2008; 7(1): 41-49.

[25] Martins DQ, Osorio WR, Souza MEP, Caram R, Garcia A. Effects of $\mathrm{Zr}$ content on microstructure and corrosion resistance of $\mathrm{Ti}-30 \mathrm{Nb}-\mathrm{Zr}$ casting alloys for biomedical applications. Electrochim Acta 2008; 53(6): 2809-17

[26] ASM International. Metalography and Microstructure Handbook. USA 1992; 9.

[27] Merrit K, Brown SA. Hypersensitivity to metallic biomaterials. $2^{\text {nd }}$ ed Boca Raton: CRC Press 1981.

[28] Airoldi G, Riva G, Vanelli M, Filippi V, Garattini G. Oral environment temperature changes induced by cold/hot liquid intake. Am J Orthod Dentofacial Orthop 1997; 112: 58-63.

[29] Mansfeld F. Simultaneous determination of instantaneous corrosion rates and tafel slopes from polarization resistance measurements. J Electrochem Soc 1973; 120(4): 515-18.

[30] Kawashima A, Asami K, Hashimoto K. An XPS study of anodic behavior of amorphous nickel-phosphorus alloys containing chromium, molybdenum or tungsten in $1 \mathrm{~m}$ CHI. Corrosion Sci 1984; 24(9): 80723.

[31] Bumgardner JD, Lucas LC. Surface analysis of nickel-chromium dental alloys. Dent Mater 1993; 9: 252-9.

[32] Roach M, Parsell D, Gardner S, Bumgardner JD. Correlation of corrosion and surface analyses for Ni-Cr alloys. Crit Rev Biomed Eng 1998; 26: 391-392.

[33] Huang HH. Effect of chemical composition on the corrosion behavior of Ni-Cr-Mo dental casting alloys. J Biomed Mater Res 2002; 60(3): 458-65.

[34] Matkovic T, Matkovic P, Malina J. Effect of Ni and Mo on the microstructure and some other propertiea of $\mathrm{Co}-\mathrm{Cr}$ dental alloys. J Alloy Compd 2004; 366: 293-7.

[35] Meticos-Hukovic M, Pilic Z, Babic R, Omanovic D. Influence of alloying elements on the corrosion stability of CoCrMo implant alloy in Hank's solution. Acta Biomater 2006: 2(6): 693-700.

[36] Moffat TP, Latanision RM. An electrochemical and x-ray photoelectron spectroscopy study of the passive state of chromium. J Electrochem Soc 1992; 139: 1869-79.

[37] Haupt S, Strehblow HH. Combined electrochemical and surface analytical investigation of the formation of passive layers. Corrosion Sci 1989; 29: 163-82

[38] Castro EB, Vilche JR. Investigation of passive layers on iron and iron chromium alloys by electrochemical impedance spectroscopy. Electrochim Acta 1993; 38(11): 1567-72.

[39] Stern M, Geary A. Electrochemical polarization. J Electrochem Soc 1957 ; 104(1) : 56-63.

[40] Jones DA. Principles and prevention of corrosion. $2^{\text {nd }}$ ed. Englewood Cliffs New Jersey: Prentice-Hall 1996

[41] Zitter H, Plenk Jr H. The electrochemical behaviour of metallic implants as an indicator of their biocompatibility. J Biomed Mater Res 1987; 21: 881-96.

[42] Pan J, Thierry D, Leygraf C. Electrochemical impedance spectroscopy study of the passive oxide film on titanium for implant application. Electrochim Acta 1996; 41(7/8): 1143-53.

[43] Huang HH. Electrochemical impedance spectroscopy study of strained titanium in fluoride media. Electrochim Acta 2002; 47(13/14): 2311-18

[44] Ismail KM, El-Egamy SS, Abdelfatah M. Effects of $\mathrm{Zn}$ and $\mathrm{Pb}$ as alloying elements on the electrochemical behavior of brass in borate solutions. J Appl Electrochem 2001; 31: 663-70.

[45] Souto RM, Alanjali M. Electrochemical characteristics of steel coated with TiN and TiAlN coating. Corrosion Sci 2000; 42: 2201-11. 